\title{
Separation of different forms of proteose peptone 3 by hydrophobic interaction chromatography with a dual salt system
}

\author{
A. Sousa, ${ }^{1}$ L. A. Passarinha, ${ }^{1}$ L. R. Rodrigues, ${ }^{2}$ J. A. Teixeira, ${ }^{2}$ A. Mendonça ${ }^{1}$ and J. A. Queiroz ${ }^{1 *}$ \\ ${ }^{1}$ CICS, Centro de Investigação em Ciências da Saúde, Universidade da Beira Interior, 6201-001 Covilhã, Portugal \\ ${ }^{2}$ IBB, Centro de Engenharia Biológica, Universidade do Minho, 4710-057 Braga, Portugal
}

Received 31 August 2007; revised 28 September 2007; accepted 29 September 2007

\begin{abstract}
A panel of four hydrophobic adsorbents (butyl-, octyl-, phenyl- and epoxy-Sepharose) was used to examine the selectivity and fractionation of several proteose peptone 3 (PP3) forms from a freeze-dried extract of whey bovine milk. In particular, the effects of altering the ligand type and salt were investigated. The chromatographic studies suggest that PP3 strongly interacts among the three commercial hydrophobic resins leading to a drop off in selectivity, while a complete binding was achieved at low salt concentrations (below $0.5 \mathrm{M}$ ) and total elution only with phosphate buffer and/or water stepwise conditions. Only in epoxy-Sepharose was an appreciably selectivity of the several fractions of PP3 present in the initial feedstock attained. Despite the high salt concentration for a complete binding of PP3 (above $1.5 \mathrm{~m}$ ammonium sulfate) onto this support, the dual salt system (ammonium sulfate $1 \mathrm{~m}$ and sodium citrate $0.8 \mathrm{~m}$ ) led to a high separation degree of high and low molecular weight forms of PP3. Copyright (C) 2008 John Wiley \& Sons, Ltd.
\end{abstract}

KEYWORDS: proteose peptone 3; hydrophobic adsorbents; dual salt system

Proteose peptone 3 (PP3) is a phosphoglycoprotein essentially isolated from the proteose peptone fraction of bovine milk (Sorensen and Petersen, 1993). The primary structure of PP3 comprises a polypeptide backbone of 135 amino acid residues containing five phosphorylated serines, two threonine-linked $O$ glycosylations and one $\mathrm{N}$-glycosylation, with an apparent molecular mass of $28 \mathrm{kDa}$ (Sorensen et al., 1997). Also, a glycoprotein with apparent molecular mass of $18 \mathrm{kDa}$ is associated with component PP3, corresponding to the 54-135 fragment released by plasmin hydrolysis in milk (Girardet et al., 1995). Several reports have shown that PP3 possesses several hydrophobic properties, particularly interesting in specific functions, such as emulsifying power, strong affinity for oil-water interface, strong foaming properties and biochemical role (Innocente et al., 1998), and a potential protective action against caries and dental acid attack (Grenby et al., 2001).

Hydrophobic interaction chromatography (HIC) is a powerful technique in modern biotechnology for the downstream processing of several biomolecules (Queiroz

*Correspondence to: J. A. Querioz, CICS, Centro de Investigação em Ciências da Saúde, Universidade da Beira Interior, 6201-001 Covilhã, Portugal.

E-mail: jqueiroz@ubi.pt

Abbreviations used: HIC, hydrophobic interaction chromatography; PP3, proteose peptone 3; WPC, whey protein concentrate. et al., 2001). HIC takes advantage of the hydrophobicity of proteins promoting its separation on the basis of hydrophobic interactions between immobilized ligands and non-polar regions on the surface of proteins (Queiroz et al., 2001). Despite the application of hydrophobic resins onto a global PP3 isolation process, e.g. octyl(Rodrigues et al., 2003) and phenyl-Sepharose (Paquet et al., 1988), this powerful chromatographic technique is not often described as the key separation method of several forms of PP3.

This work was performed with a whey protein concentrate (WPC) extract with an $80 \%$ (w/w; dry basis) protein content obtained from Quinta dos Ingleses, Lda (Portugal). Initially, this WPC was dissolved in phosphate buffer $20 \mathrm{~mm}, \mathrm{pH} 7.0$ and it was precipitated in $50 \%$ ammonium sulfate. The HIC stationary phases on analysis were butyl-Sepharose 4FF, octyl- and phenylSepharose 6FF purchased from GE Healthcare Biosciences and epoxy-Sepharose CL-6B prepared by covalent immobilization of 1,4-butanediol diglycidyl ether on Sepharose CL-6B according to the protocol of Sundberg and Porath (1974). The four hydrophobic media were packed according to company guidelines $(11 \mathrm{~mL}$ of gel volume) into a $\mathrm{C}_{16}$ glass column purchased from GE Healthcare Biosciences. All buffers pumped in an FLPC system (Amersham Biosciences, Uppsala, Sweden) were filtered through a $0.20 \mu \mathrm{m}$ pore size membrane (Schleicher Schuell, Dassel, Germany) and degassed 
Table 1. Selectivity, adsorption and elution conditions of PP3 on four hydrophobic adsorbents

\begin{tabular}{|c|c|c|c|c|}
\hline \multirow[b]{2}{*}{ Ligand } & \multirow[b]{2}{*}{$\begin{array}{l}\text { Ligand capacity } \\
(\mu \mathrm{mol} / \mathrm{mL})\end{array}$} & \multicolumn{2}{|c|}{$\begin{array}{l}\text { [Ammonium sulfate] } \\
(\mathrm{M}) \text { in buffer }\end{array}$} & \multirow[b]{2}{*}{ Selectivity } \\
\hline & & $\begin{array}{l}\text { Adsorption } \\
\text { PP3 }\end{array}$ & Elution PP3 & \\
\hline Epoxy & $-^{\mathrm{b}}$ & $\geq 1.5$ & 0.5 & + \\
\hline Octyl & 5 & 0.5 & Water & - \\
\hline Phenyl & 40 & 0.5 & Water & - \\
\hline Butyl & 50 & $\geq 0.5$ & 0 & $-1+$ \\
\hline
\end{tabular}

${ }^{\text {a }}$ Data obtained from the product specification sheets from GE Healthcare Biosciences.

b $500 \mu \mathrm{mol} / \mathrm{g}$ dried gel.

$(-)$ and $(+)$ denote low and high selectivity degrees, respectively, in fractionation of several PP3 forms.

ultrasonically. Unless otherwise stated, the columns were initially equilibrated with $\left(\mathrm{NH}_{4}\right)_{2} \mathrm{SO}_{4}$ in $20 \mathrm{~mm}$ of phosphate buffer $\mathrm{pH}$ 7.0. Subsequently, aliquots of PP3 supernatant $(300 \mu \mathrm{L})$ were loaded onto the columns by an isocratic elution mode of $1 \mathrm{~mL} / \mathrm{min}$ at room temperature. After elution of non-bound species, the concentration of $\left(\mathrm{NH}_{4}\right)_{2} \mathrm{SO}_{4}$ was decreased to zero within a step mode, in order to elute the bound proteins. The chromatographic run was concluded with a final elution step using water for an effective wash of the resin. In all separations and throughout the entire chromatographic run the optical density was monitored at $280 \mathrm{~nm}$, while $3 \mathrm{~mL}$ fractions were collected, pooled and concentrated using Vivaspin concentrators (Vivascience). Samples were analyzed by sodium dodecyl sulfatepolyacrylamide gel electrophoresis (SDS-PAGE) according to the method described by Laemmli (1970).

A comparative study of the four hydrophobic resins was performed in order to examine the PP3 interaction under several operating conditions that lead to distinct binding affinities and elution environments, and allow the best accurate fractionation and selectivity performance of several weight molecular forms of PP3 present in the crude extract.

The results (Table 1) show that PP3 is totally retained onto the butyl support at a moderate ionic strength $(>0.5 \mathrm{M})$. However, on phenyl and octyl resins, mainly due to the elongation of $n$-alkyl chain (octyl) and the introduction of aromatic groups in the ligands (phenyl), PP3 is completely bound at low ionic strengths $(0.5 \mathrm{M})$, and elutes only with water, leading to an insufficient fractionation. Nevertheless, with a mild hydrophobic ligand, such as epoxy (Tomaz et al., 2002), a higher selectivity was obtained in spite of the high and moderate adsorption and elution conditions, respectively (Table 1). This selective behavior was previously observed with other enzymes, namely cellulases (Tomaz et al., 2002) and human catechol- $O$-methyltransferase (Passarinha et al., 2007). Subsequently, we tested the effect of different salts (sodium sulfate, sodium phosphate and sodium citrate) that led to different ionic strengths (identical cation, different anion) and probably distinct separation degrees on the chromatographic step. Indeed, Melander and Horváth (1977) have claimed that the most relevant parameters which define the effect of salt on the retention in HIC are the molality and the molal surface increment of the salt. In this work, sodium citrate is described as the more effective salt for obtaining chromatographic retention; however its application in HIC is unusual.

Our experiments with epoxy-Sepharose reveals that sodium citrate promotes the total retention of PP3 with a relative lower concentration $(1.2 \mathrm{M}$; data not shown), while with ammonium sulfate more than $1.5 \mathrm{M}$ is necessary. Ammonium sulfate is the classical salt applied in HIC, but in light of these considerations, a dual salt system was tested with an epoxy-Sepharose support (ammonium sulfate $1 \mathrm{M}$ and sodium citrate $0.8 \mathrm{M}$ ), in order to promote the total retention of PP3. In fact, these salt conditions are a new approach in HIC performance. After several experiments, it was concluded that the best operational setup in the epoxy-Sepharose support is the retention at $100 \%$, followed by two intermediate steps at 70 and $50 \%$, and final elution at $0 \%$ of buffer A by a step mode gradient [Fig. 1(A)]. The screening of proteins on the chromatographic profile reveals that the portion eluted at $70 \%$ contains mainly a $18 \mathrm{kDa}$ fraction of PP3; the $36 \mathrm{kDa}$ fraction was eluted at $50 \%$ and the highest molecular weight (60 and $78 \mathrm{kDa}$ ) fractions were eluted at $0 \%$ of buffer A [Fig. 1(B)]. These results were confirmed by western Blotting (data not shown), since the anti-PP3 antibody exhibits reactivity near the same protein standards.

This work shows that, for the three commercial hydrophobic resins, a complete binding of PP3 was achieved at low salt concentrations of ammonium sulfate $(\leq 0.5 \mathrm{M})$; however the higher protein-ligand interaction observed in octyl and phenyl ligands led to 


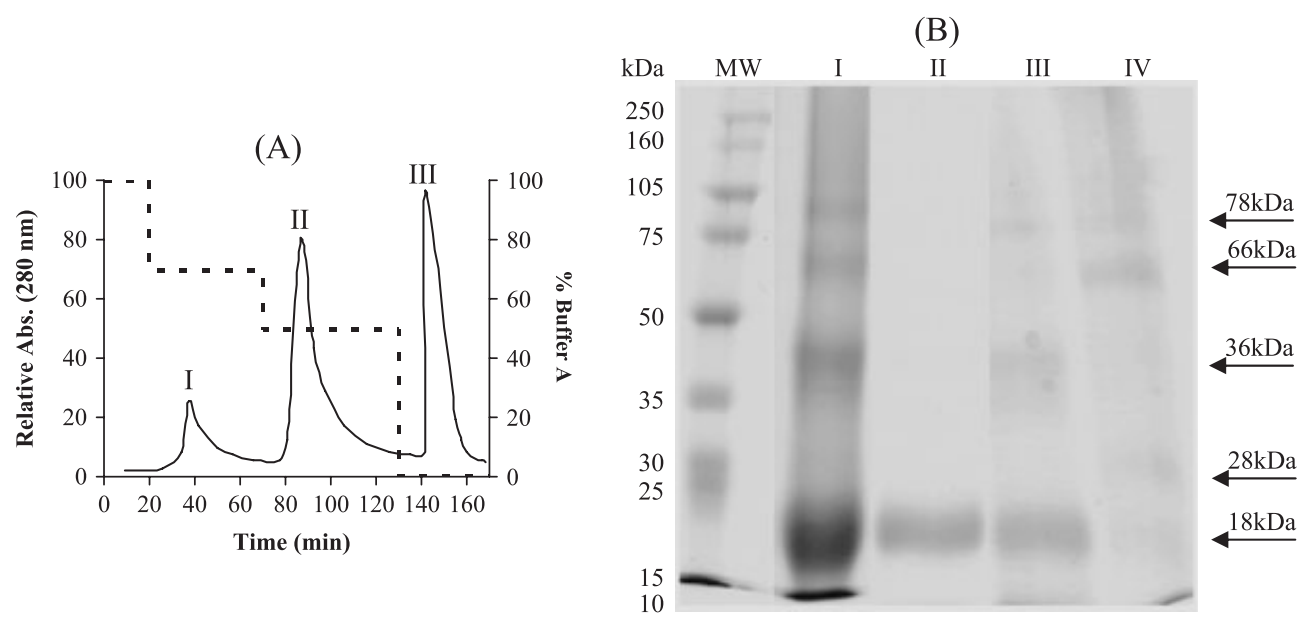

Figure 1. (A) Chromatographic profile of a WPC extract on epoxy-Sepharose CL-6B in a dual salt system with a step salt gradient at 100, 70, 50 and $0 \%$ buffer A (buffer A, ammonium sulfate $1 \mathrm{~m}$ and sodium citrate $0.8 \mathrm{M}$ in $20 \mathrm{~mm}$ phosphate buffer, $\mathrm{pH} 7.0$; buffer $\mathrm{B}$, phosphate buffer $20 \mathrm{~mm}, \mathrm{pH}$ 7.0). (B) SDS-PAGE of PP3 chromatographic fractions. The samples analyzed were (I) PP3 extract after ammonium sulfate precipitation; (II) pool of fractions eluted at $70 \%$ buffer A; (III) pool of fractions eluted at $50 \%$ buffer A; (IV) pool of fractions eluted at $0 \%$ buffer A. The positions of the different fractions and aggregates of PP3 are indicated by the arrows.

a decrease in selectivity (total elution only with phosphate buffer and/or water). Nevertheless, an optimized stepwise gradient with a dual salt system (ammonium sulfate and sodium citrate) proved to be the most useful to obtain different degrees of hydrophobicity and attractive selectivity of all PP3 fractions present in the WPC. To the best of our knowledge this is the first report on HIC applying a dual salt system strategy. This method may be of general application and in particular where the presence of multi-forms of PP3, caseins and other individual components of milk is problematic.

\section{Acknowledgments}

The kindly collaboration of Professor E. S. Sorensen (University of Aarhus, Denmark), by providing us the rabbit anti-bovine PP3 immunoglobulin for western blotting assays, is gratefully acknowledged.

\section{REFERENCES}

Girardet JM, Coddeville B, Plancke Y, Strecker G, Campagna S, Spik G and Linden G. Structure of glycopeptides isolated from bovine milk component PP3. European Journal Biochemistry 1995; 234: 939-946.

Grenby TH, Andrews AT, Mistry M and Williams RJH. Dental caries-protective agents in milk and milk products: investigations in vitro. Journal of Dentistry 2001; 29: 83-92.

Innocente $\mathrm{N}$, Corradini $\mathrm{C}$, Blecker $\mathrm{C}$ and Paquot M. Emulsifying properties of the total fraction and the hydrophobic fraction of bovine milk proteose-peptones. International Dairy Journal 1998; 8: 981-985.

Laemmli UK. Cleavage of structural proteins during the assembly of the head of bacteriophage T4. Nature 1970; 227: 680-685.

Melander W and Horváth C. Salt effects on hydrophobic interaction in precipitation and chromatography of proteins: an interpretation of lyotropic series. Archives of Biochemistry and Biophysics 1977; 183: $200-215$

Paquet D, Nejjar Y and Linden G. Study of a hydrophobic protein fraction isolated from milk proteose-peptone. Journal of Dairy Science 1988; 71: 1464-1471.

Passarinha LA, Bonifácio MJ and Queiroz JA. Comparative study on the interaction of recombinant human soluble catechol- $O$ methyltransferase on some hydrophobic adsorbents. Biomedical Chromatography 2007; 21: 430-438.

Queiroz JA, Tomaz CT and Cabral JMS. Hydrophobic interaction chromatography of proteins. Jounal of Biotechnology 2001; 87: 143-159.

Rodrigues LR, Venâncio A and Teixeira JA. Recovery of the proteose peptone component 3 from cheese whey in Reppal PES 100/polyethylene glycol aqueous two-phase systems. Biotechnology Letters 2003; 25: 651-655.

Sorensen ES and Petersen TE. Phosphorylation, glycosylation and amino acid sequence of component PP3 from the proteose peptone fraction of bovine milk. Journal of Dairy Research 1993; 60: 535542.

Sorensen ES, Rasmussen LK, Moller L and Petersen TE. The localization and multimeric nature of component PP3 in bovine milk: purification and characterization of PP3 from caprine and ovine milks. Journal of Dairy Science 1997; 80: 3176-3181.

Sundberg L and Porath J. Preparation of adsorbents for biospecific affinity chromatography. Attachment of group-containing ligands to insoluble polymers by means of means of bifuctional oxiranes. Journal of Chromatography A 1974; 90: 87-98.

Tomaz CT, Duarte D and Queiroz JA. Comparative study on the fraction of cellulases on some hydrophobic interaction chromatography adsorbents. Journal of Chromatography A 2002; 944: 211 216. 